Colloque C2, suppl. au Journal de Physique II, Vo1. 1, septembre 1991

\title{
SAFETY AND ENVIRONMENTAL ASPECTS OF CVD
}

\author{
R.H. WALIING and R.H. MOSS \\ BT Laboratories, Martlesham Heat, Ipswich, GB-Suffolk IP5 7RE, \\ Great-Britain
}

\begin{abstract}
Early concerns over the handling of toxic materials related primarily to the safety of the operator. Safety procedures relating to prevention of ingestion, inhalation and skin contact, have been developed and in the field of CVD processing, many good standard practices are being used. Frequently, the safety procedures adopted for dealing with toxic gases and fumes rely on dilution in a forced air extraction enclosure to a level which under normal operating conditions reduce the toxic gas concentration to levels below the maximum exposure limit (MEL). Today, however, much more attention is being paid to the environmental issues and simply to dilute toxic fumes is no longer considered an acceptable practice. Handling of liquid and solid toxic waste products also poses concerns regarding final safe disposal, and the techniques employed as part of the CVD process for removal of toxic waste will impact significantly on this.
\end{abstract}

This paper considers the issues involved in handling of toxic gases and particularly techniques for scrubbing gas effluent. The types of scrubber commonly used will be discussed and the results reported on two types of commercially available scrubbers that have been used on MOCVD systems in our labortories. In addition we will consider the opportunities for replacing some of the highly toxic gases with less hazardous materials and report on current progress with substitutes for arsine and phosphine. Finally we will propose some general principles for reviewing and defining procedures for safe handling of waste gases. 